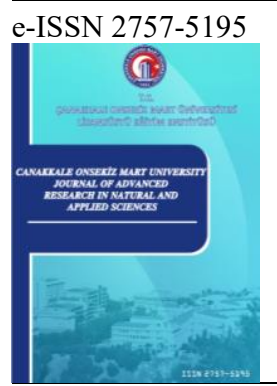

Çanakkale Onsekiz Mart University

Journal of Advanced Research in Natural and Applied Sciences

Open Access

\title{
Garp Linyitleri İşletmesi (GLİ) Şlam Kömürlerinin Spiral ile Zenginleştirilebilirliğine Tane Boyutunun Etkisi
}

\author{
Ali Uçar ${ }^{1, *}$, Sevgi Karaca ${ }^{1}$, Nezahat Ediz $^{1}$, Oktay Şahbaz ${ }^{1}$ İ.Göktay Ediz ${ }^{1}$ \\ ${ }^{1}$ Maden Mühendisliği Bölümü, Mühendislik Fakültesi, Kütahya Dumlupınar Üniversitesi, Kütahya, Türkiye
}

$\begin{array}{ll}\text { Makale Tarihçesi } \\ \text { Gönderim: } & 19.11 .2020 \\ \text { Kabul: } & 24.03 .2021 \\ \text { Yaylm: } & 30.06 .2021\end{array}$

Araștırma Makalesi

\begin{abstract}
$\ddot{O} \mathbf{z}-\mathrm{Bu}$ çalışmada Garp Linyitleri İşletmesi Tunçbilek Lavvarına ait olan ve yaklaşık 4 milyon $\mathrm{m}^{3}$ kapasiteli 4 Nolu şlam göletindeki atığın değerlendirilebilirliği araştııılmıştır. Bu amaçla artıktaki kömürün kazanılabilme alternatifleri incelenmiş ve ülkemizde ince kömürlerin zenginleştirilmesinde yaygın olarak kullanılan spiral yöntemi seçilmiştir. Şlam göletinden alınan örneklerle yapılan deneyler sonucunda malzemenin yaklaşık $-5 \mathrm{~mm}$ boyutlu ve $\% 68.01$ kül içerikli olduğu belirlenmiştir. Zenginleştirme çalışmaları için numuneler $+1 \mathrm{~mm},-1+0.212 \mathrm{~mm},-0.212+0.038 \mathrm{~mm}$ ve $-0.038 \mathrm{~mm}$ boyut gruplarına ayrılmıştır. $+1 \mathrm{~mm}$ boyut grubunun termik santraller için yeterli karbon içeriğine (\%77.84) sahip olması, $-0.038 \mathrm{~mm}$ boyut grubunun ise zenginleştirmeyi olumsuz yönde etkileyecek şekilde çok ince boyutta ve yüksek kül içeriğine sahip olması (\%69.66 kül) nedeniyle deneylerde kullanılmamıştır. Şlam göleti atıklarının spiral ile zenginleştirilmesinde katı oranı ve besleme debisi gibi parametreler değiştirilerek deneyler yapılmıştır. Deneyler sonucunda en iyi değerler, $-1+0.212 \mathrm{~mm}$ boyut grubunda, $\% 30$ katı oranında ve $15 \mathrm{l} / \mathrm{dk}$ besleme debisinde elde edilmiştir. $-0.212+0.038 \mathrm{~mm}$ boyut grubunda ise katı oranının artması karbon içeriğini olumsuz etkilemiş ve en iyi değerler, $\% 20$ katı oranı ve $15 \mathrm{l} / \mathrm{dk}$ besleme debisinde elde edilmiştir. Ayrıca, $+1 \mathrm{~mm}$ boyutlu ürün ile deneylerden elde edilen konsantre karıştırılarak sonuçları birlikte değerlendirilmiştir. Böylece \%68.98 oranında karbon içerikli temiz kömür, \%56.77 yanabilir verim ve $4712.31 \mathrm{kcal} / \mathrm{kg}$ üst $1 s 1$ değeri ile kazanılmıştır.
\end{abstract}

\section{The Effect of Particle Size on the Beneficiation of Coal Slimes of Western Lignite Company (WLC) by Spiral}

\author{
${ }^{1}$ Department of Mining Engineering, Faculty of Engineering, Kutahya Dumlupinar University, Kutahya, Turkey
}

\section{Article History \\ Received: $\quad 19.11 .2020$ \\ Accepted: $\quad 24.03 .2021$ \\ Published: $\quad 30.06 .2021$}

Research Article

\begin{abstract}
In this research, beneficiation of coal slimes taken from the waste pond of Tuncbilek Coal Washery at WLC (Number-4) with a capacity of 4 million $\mathrm{m}^{3}$ was investigated. For this purpose, beneficiation alternatives were investigated and spiral method was chosen which is commonly used for the beneficiation of fine coals in Turkey. It was determined that the coal slimes had an average particle size of $-5 \mathrm{~mm}$ and an ash content of $68.01 \%$ from the analysis made. The slimes were classified into $+1,-1+0.212,-0.212+0.038$ and $-0.038 \mathrm{~mm}$ particle size groups. The $-0.038 \mathrm{~mm}$ material was excluded from the tests due to the high ash content ( $30.34 \%$ carbon content) and ultra-fineparticle size which are thought to affect the processes negatively, in addition the availability of $+1 \mathrm{~mm}$ materials with suitable ash content $(77.84 \%$ carbon content) for the power plant. Experiments were carried out changing the parameters such as solid ratio and feed rate for the beneficiation of the coal slimes. The best results were obtained on the $-1+0.212$ particle size group, at $30 \%$ solid ratio and $15 \mathrm{l} / \mathrm{min}$ feed rate. Increased solid ratio exacerbated the ash content for $-0.212+0.038 \mathrm{~mm}$ size group and the best result was obtained at $20 \%$ solid ratio and $15 \mathrm{l} / \mathrm{min}$ feed rate. Moreover, $+1 \mathrm{~mm}$ material was mixed up with the beneficiated coal and the result were evaluated together. Hence, a clean coal with an carbon content of $68.98 \%$, a combustible recovery of $56.77 \%$ and an upper calorific value of $4712.31 \mathrm{kcal} / \mathrm{kg}$ was achieved.
\end{abstract}

Keywords - Western lignite company, spiral, slime pond, slime enrichment, particle size

\footnotetext{
1 (1) ali.ucar@dpu.edu.tr

2 (D) sevgi.karaca@dpu.edu.tr

3 (D) nezahat.ediz@dpu.edu.tr

4 (1) oktay.sahbaz@dpu.edu.tr

5 (D) goktay.ediz@dpu.edu.tr

*Sorumlu Yazar / Corresponding Author
} 


\section{Giriş}

Dünya kömür tüketiminin yaklaşık olarak \%69’u elektrik ve ticari 1sı üretiminde, \%13'ü demir-çelik endüstrisinde, \%3’ü isınmada ve \%15'i diğer sanayi sektörlerinde kullanılmaktadır (IEA, 2018).Metin

Dünyada enerji üretiminde en çok kullanılan kömürün görünür rezervi 1.07 trilyon ton olup, alt bitümlü kömür ve linyit rezervi görünür rezervin \%30’unu oluşturmaktadır. Türkiye^deki linyit kaynak rezervi ise 19.32 milyar tondur. Bu rezervin büyük bir kısmı Afşin-Elbistan'da bulunurken, Ege Bölgesi linyitleri bunu izlemektedir. Türkiye'de üretilen linyit kömürünün büyük bir kısmı termik santrallerde elektrik üretimi amaciyla kullanılmaktadır (TKİ, 2019).

Linyit kömürünün termik santrallerde kullanılabilmesi için belirli kalori değerleri değerlerine sahip olması gerekmektedir. GLİ tarafından Çelikler Tunçbilek B Grubu Termik Santrali’ne beslenen tüvenan kömür/mikst için protokol değerleri Tablo 1'de görülmektedir.

Tablo 1

Çelikler Tunçbilek B Grubu Termik Santrali’ne beslenen tüvenan kömür/mikst değerleri

\begin{tabular}{c|ccccc}
\hline $\begin{array}{c}\text { Baz AID } \\
(\mathrm{Kcal} / \mathrm{Kg})\end{array}$ & $\begin{array}{c}\text { En Yüksek AID } \\
(\mathrm{Kcal} / \mathrm{Kg})\end{array}$ & $\begin{array}{c}\text { En Düşük AID } \\
(\mathrm{Kcal} / \mathrm{Kg})\end{array}$ & $\begin{array}{c}\text { Nem } \\
(\%)\end{array}$ & $\begin{array}{c}\text { Kül } \\
(\%)\end{array}$ & $\begin{array}{c}\text { Tane Boyu } \\
(\mathrm{mm})\end{array}$ \\
\hline 2350 & 3000 & 1900 & $24( \pm \% 10)$ & $42( \pm \% 10)$ & $0-1000$ \\
\hline
\end{tabular}

Kömür içinde kükürt ve diğer inorganik bileşik maddeler bulunmakta, üretim ve yakılması sırasında bu maddeler açığa çıkarak çevreyi kirletmektedir. Bu nedenle özellikle gelişmiş ülkelerin uyguladığı çevre kanunlarında, doğanın kirlenmesini önleyecek bir takım kısıtlamalar getirilmiştir. Temiz yakıt tüketiminin zorunlu kılındığı bu yöntemler kömür yıkamanın önemini artırmıştır.

Kömür yıkama yöntemleri iri ve ince kömürler için farkl1lık göstermektedir. İri boyutlar için gravite yöntemleri, ince boyutlar için ise genellikle flotasyon ve spiral yöntemi uygulanmaktadır (Güney, Ateşok, Önal ve Altaş, 1996; Meenan, 1999). İri boyutlar için gravite yöntemleri, yüksek verimlilik ve düşük maliyet nedeniyle kömür zenginleştirmede yaygın olarak kullanılmaktadır. İnce kömür zenginleştirmede ( $-0.5 \mathrm{~mm})$ uygulanan flotasyon işleminde ise kullanılan kimyasallardan dolayı yüksek maliyetler oluşmaktadır. Dolayısıyla kömürdeki külü azaltmak amacıyla yeni teknolojiler araştırılmış ve araştırılmaya devam etmektedir (Peer, Mongwe ve Van Heerden, 2002; Uslu, Sahinoglu ve Yavuz 2012). Son yıllarda mineraller arasındaki yoğunluk farkına dayanan gravite esaslı ayırıcılara ek olarak MGS, Kelsey jigi, Falcon ve Knelson konsantratörü gibi santrifüj kuvvetinden de yararlanılarak zenginleştirme yapan aletler kullanılmaktadır (Çiçek, Cöcen, Engin ve Cengizler, 2008; Erdem vd.,2012; Honaker, Wang ve Ho,1996; Koca, Koca ve Karaoglu, 2000; Özgen, Malkoç, Doğancik, Sabah ve Şapçi, 2011; Sivrikaya, 2014; Uslu vd., 2012). Fakat bu cihazlarında daha fazla su gerektirmesi, yüksek sermaye ve işletme maliyetleri gibi dezavantajları bulunmaktadır.

Spiraller, metalik cevherler, endüstriyel mineraller, sahil kumları ve kömür zenginleştirmede dünya çapında yaygın olarak kullanılmaktadır (Burt, 1984; Glass, Minekus ve Dalmun 1999; Holland-Batt, 1995; Ramsaywok, Vermaak ve Viljoen 2010; Richards ve Palmer, 1997). Spiraller yoğunluk ve tane şekli birbirinden farklı olmak şartıyla, genellikle $-2+0.030 \mathrm{~mm}$ arasındaki, belirli bir serbestleşme derecesine sahip taneleri birbirinden ayırmak için kullanılır (Holland-Batt, 1995; Richards ve Palmer, 1997). Bu zenginleştiricilerde besleme olarak kullanılan malzemenin tane boyut dağılımı, şlam miktarı, serbestleşme derecesi, beslemenin içerdiği katı miktarı, besleme içerisindeki malzemelerin yoğunluğu, tane şekli gibi birçok özellik spiraldeki akış davranışını değiştirerek ayrımı etkileyen değişkenlerdir (Burt, 1984; Falconer, 2003). Spirallerin tasarım parametreleri; spiralin kesit alanının yapısı, oluğun çapı, sarmalın eğimi, sarmal sayısı, spiralin uzunluğu, spiralin yüzey özellikleri, bölücü bıçak pozisyonları ve yıkama suyu olarak sinıflandırılabilmektedir. 
Ekonomikliği, hareketli parçasının olmayışı, basit yapısı gibi öne çıkan avantajları ile spiral kullanılarak kömürdeki kül yapıcı maddelerin uzaklaştırılması pek çok araştırmacının ilgisini çekmiştir Düşük kül içerikli numuneler ile yapılan çalışmalarda yanabilir verimler daha yüksek olurken kül içeriği yükseldiğinde yanabilir verim değeri daha düşük olduğu görülmektedir (Glass vd., 1999; Honaker, Jain, Parekh ve Saracoglu, 2007; Öney, Tanrıverdi ve Çiçek 2014).

Öney vd. (2014), -1+0.150 mm boyut grubunda yaptı̆̆ taşkömürü deneylerinde, spirali \%25, \%30 ve \%35 katı oranlarında çalıştırmıştır. Deney sonuçlarına göre $\% 25$ katı oranında $\% 28.72$ kül içerikli kömürü, $\% 13.28$ kül oranı ve \%92.07 yanabilir verim ile kazanmıştır.

Honaker vd. (2007) -0.210+0.044 mm boyutlu ve \%33.5 küllü kömürü kullanarak spiral deneyleri yapmıştır. Yaptıkları çalışmada 3 seviyeli Box-Behnken deney tasarımını kullanmışlardır. Deney tasarımında besleme akış hızı, katı oranı ve bıçak açısı parametrelerini kullanarak elde ettikleri sonuçlara göre, $\% 11.71$ küllü temiz kömürü \%84 yanabilir verim ile kazanmıştır.

Sivrikaya (2014), -1.5 mm boyutlu \%40 küllü Tunçbilek kömürünü \%20, \%25 ve \%30 katı oranlarında Reichert spiraline beslemiş ve \%18.28 küllü, $5582 \mathrm{kcal} / \mathrm{kg}$ 1s1l değere sahip temiz kömür elde etmiş̧tir.

GLİ Tunçbilek Lavvarı, 1952 yılından 2001 yılına kadar 4 Nolu şlam göletine tesis artığını depolamıştır. Kömür üretiminde kullanılan mekanize kazı yöntemlerinin artması ve sonrasında uygulanan işlemler ince kömür oluşumuna ve tesis performanslarının düşmesine neden olmaktadır. Böylece çok fazla miktarda kömür, artıkla beraber artık barajlarına boşaltılmaktadır. Ayrıca, 4 Nolu artık göleti multi siklon grup (MSG) tesise ilave edilmeden önce de kullanıldığı için şlam göleti içinde kalorisi nispeten yüksek iri kömürler de bulunmaktadır. Bu durum, ekonomik kaybın yanı sıra artık barajlarında depolanma nedeniyle ciddi çevresel problemleri de beraberinde getirmektedir (Chaurasia ve Nikkam, 2016).

4 Nolu artık göleti şlam kömürünün termik santrallerde kullanımı susuzlaştırma maliyetleri ve yetersiz kalori içeriği nedeniyle mümkün olamamaktadır. Bunun yanı sıra yönetmeliğin getirdiği ağır şartlara bağlı olarak artıkların depolanma maliyetleri de oldukça yüksektir. İşletme çevresindeki birçok barajın dolu olduğu (yaklaşı 18 milyon $\mathrm{m}^{3}$ 'lük artık miktarı) ve yeni oluşturulan eski açık ocak çukurlarının da hızla dolduğu düşünüldügünde mevcut yöntemlerle zenginleştirilemeyen bu ince kömürlerin geri kazanılması yine ekonomik ve çevresel açıdan gereklidir.

GLİ tüvenan kömüründen külün uzaklaştırması ve tesis artı̆̆ından kömür kazanımı ile ilgili çeşitli fiziksel ayırıcılar kullanılarak zenginleştirme çalışmaları yapılmıştır. Bu çalışmada ise Lavvar kurulumundan itibaren tesisten çıkan artığın ve MSG kurulmadan önce sistemden kaçak olarak artık göletine giden malzemenin zenginleştirilebilirliği araştırılmıştır. Diğer fiziksel zenginleştirme yöntemlerine göre avantajlı olan spiralin kullanıldığı bu çalışmada, tane boyutunun yanı sıra katı oranı ve besleme debisi gibi parametrelerin kömürün kazanılabilirliğine etkisi de incelenmiştir. Ayrıca geri kazanılan kömürün termik santralde kullanılabilirliği değerlendirilmiştir.

\section{Materyal ve Yöntem}

Deneylerde kullanılan kömür numunesi, Türkiye Kömür İşletmeleri A.Ş.'ye ait GLİ bünyesindeki 4 Nolu olarak adlandırılan artık göletinden temin edilmiştir. Dumlupınar Üniversitesi Maden Mühendisliği Bölüm Laboratuvarına getirilen yaklaşık 400 kg'lık artık göleti numunesi laboratuvarda karıştırılarak homojen hale getirilmiştir. Daha sonra numune konileme-dörtleme yöntemi ile bölünerek depolanmıştır. Bu numunenin bir kısmı kimyasal ve boyut analizleri için kullanılmıştır.

Artık gölet numunesinin boyut aralıklarına göre madde miktarı dağılımını belirlemek için elek analizi yapılmıştır ve elde edilen sonuçlar Şekil 1'de verilmiştir. Bu sonuçlara göre artık göletindeki malzemenin yaklaşı olarak $5 \mathrm{~mm}$ 'den daha ince olduğu ve $0.038 \mathrm{~mm}$ altındaki malzemenin ise \%69.56 oranında bulunduğu tespit edilmiştir. 
Artık gölet numunesinin tane boyut gruplarına göre nem, kül, kükürt, üst 1sıl değer (ÜID) ve alt 1sıl değer (AID) analizleri de yapılmıştır ve elde edilen sonuçlar Tablo 2'de verilmiştir. Nem değerleri Moisture Analyzer AND ML-50 cihazında ölçülmüştür. Kül analizleri Nüve marka kül fırınında, kükürt analizi Leco SC 144 DR cihazında ve kalori ölçümleri Ika Werke cihazında gerçekleştirilmiştir.

Tablo 2 incelendiğinde, $0.038 \mathrm{~mm}$ boyutun altındaki numunede toplam kükürt değerinin önemli miktarda azaldığı dikkat çekmektedir. Yani kükürdün büyük oranlarda bu boyutun üstünde olduğu ve daha çok kömüre bağlı olduğu anlaşılmaktadır. Ayrıca genel olarak tane boyutunun düşmesine bağlı olarak kül değerlerinin arttı̆̆ı ve kalori değerlerinin azaldığı gözlenmektedir, bu da beklenen bir durumdur.

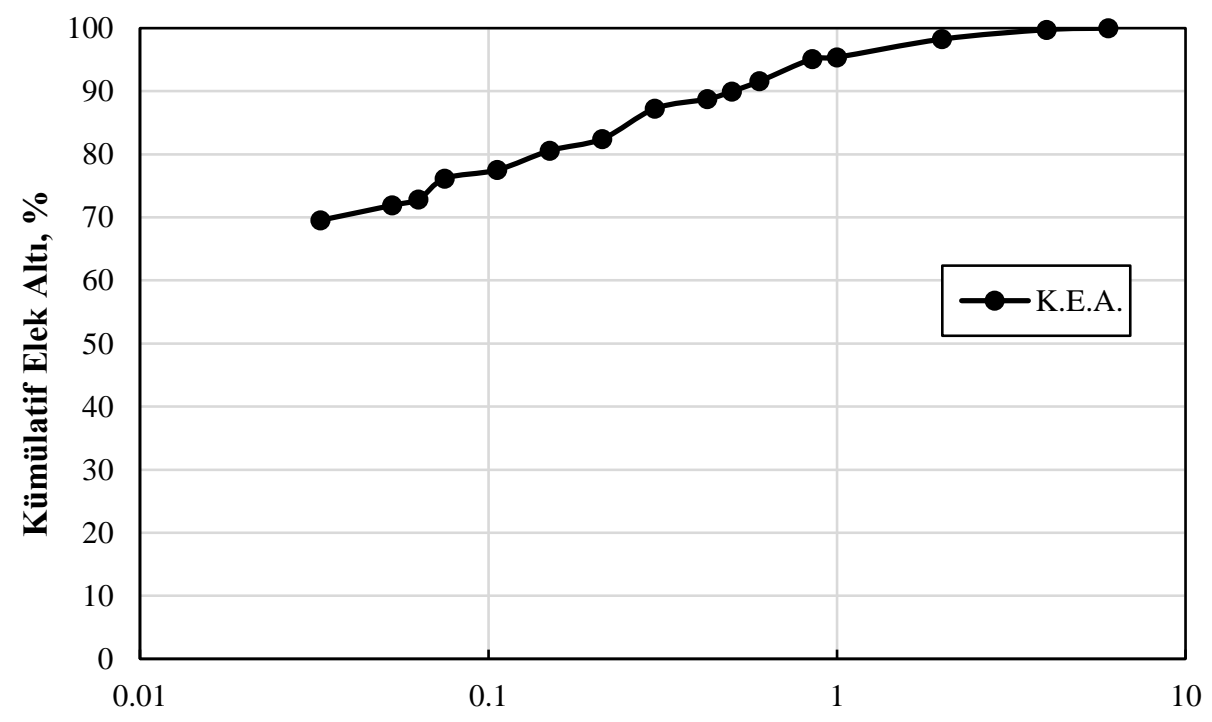

Tane Boyut, mm

Şekil 1. 4 Nolu gölet artı̆̆ına ait kümülatif elek altı eğrisi

Tablo 2

4 Nolu gölet numunesinin nem, kül, kükürt ve 1s1l değerleri

\begin{tabular}{l|rccccc}
\hline Tane Boyutu (mm) & Ağırlık (\%) & Kül (\%) & ÜID (Kcal/kg) & AID (Kcal/kg) & Kükürt (\%) & Nem(\%) \\
\hline+4 & 0.24 & 27.25 & 5191 & 4763 & 1.07 & 3.8 \\
$-4+2$ & 1.5 & 24.83 & 5441 & 4944 & 1.16 & 4.7 \\
$-2+1$ & 2.87 & 20.41 & 5731 & 5233 & 1.19 & 4.3 \\
$-1+0.85$ & 0.24 & 25.45 & 5170 & 4710 & 1.23 & 4.3 \\
$-0.85+0.5$ & 5.16 & 23.46 & 5403 & 4925 & 1.25 & 4.3 \\
$-0.5+0.3$ & 2.75 & 30.52 & 4936 & 4501 & 1.23 & 4.3 \\
$-0.3+0.15$ & 6.64 & 39.41 & 4561 & 4166 & 1.33 & 4.4 \\
$-0.15+0.075$ & 4.41 & 47.38 & 3757 & 3498 & 1.42 & 2.6 \\
$-0.075+0.038$ & 6.63 & 48.26 & 2255 & 2878 & 1.21 & 3.2 \\
-0.038 & 69.56 & 81.91 & 431 & 295 & 0.64 & 1.6 \\
\hline
\end{tabular}

Spiral ile zenginleştirme deneyleri için artık göleti numuneleri $+1 \mathrm{~mm},-1+0.212 \mathrm{~mm},-0.212+0.038 \mathrm{~mm}$ ve $0.038 \mathrm{~mm}$ boyut gruplarına ayrılmıştır. Kil içeriği yüksek ve çok ince boyutlu $-0.038 \mathrm{~mm}$ 'lik kısım, zenginleştirmeyi olumsuz yönde etkileyebileceğinden deneylerde kullanılmamıştır. $+1 \mathrm{~mm}$ boyut grubu ise termik santraller için yeterli karbon içeriğine (\%77.84) sahip olması nedeniyle zenginleştirme işlemine tabi tutulmamıştır. Böylece deneylerde $-1+0.212 \mathrm{~mm}$ ve $-0.212+0.038 \mathrm{~mm}$ tane boyut gruplarındaki malzemeler kullanılmıştır. Her tane boyut grubu için besleme katı oranı ve debisinin, karbon içeriği ile yanabilir verim üzerine 
etkisi belirlenmeye çalışılmıştır. Deneylerde Humprey spirali, \%10, \%20 ve \%30 katı oranları ile 5 1/dk, 10 1/dk ve 15 l/dk besleme debilerinde kullanılmıştır. Bıçak açısının sabit tutulduğu deneylerde süreye bağlı olarak artık ve konsantre alınmıştır. Ürünler filtre edilip kurutularak tartılmış ve kül analizleri yapılmıştır.

\section{Bulgular ve Tartışma}

$-1+0.212 \mathrm{~mm}$ boyut grubunda yapılan spiral ile zenginleştirme deneyleri sonucunda elde edilen temiz kömürün karbon içeriği değerleri Şekil 2'de ve yanabilir verim değerleri Şekil 3’te verilmiştir.

Şekil 2 ve Şekil 3 birlikte incelendiğinde, 5 ve 10 1/dk besleme debilerinde, katı oranının artmasına bağlı olarak temiz kömürdeki karbon içeriği ve yanabilir verim değerlerinde önemli bir değişimin olmadığı görülmektedir. Ancak 15 1/dk besleme debisinde ve \%20 katı oranında çalışıldığında, temiz kömürdeki karbon içeriği değeri \%76.81 gibi bir değere düşmektedir. Bunun nedeni olarak, besleme debisi ve katı oranının artışıyla birlikte şiste gitmesi gereken kısmın, temiz kömür içine gelmesi gösterilebilir. 15 1/dk besleme debisi ve \%20 katı oranında yanabilir verimin \%95.92'e yükselmesi de bu düşünceyi desteklemektedir.

$-1+0.212 \mathrm{~mm}$ tane boyut grubunda, \%30 katı oranı ve $10 \mathrm{l} / \mathrm{dk}$ besleme debisi ile çalışılan deney şartları optimum olarak kabul edilmiştir. Bu şartlarda \%81.74 karbon içeriği değerine sahip temiz kömür, \%93.09 yanabilir verim ile elde edilmiştir.

Sivrikaya (2014) tarafından yapılan \%40 küllü, $-1.5+0.150 \mathrm{~mm}$ boyutlu Tunçbilek tüvenan kömürü ile yapılan çalışmada, farklı besleme hızı ve katı oranlarının verim üzerine etkisi araştııılmıştır. Besleme katı oranı ve hızı arttıkça şiste gitmesi beklenen taneler konsantreye gitmekte ve bu da yanabilir verimi kötü yönde etkilemiştir (Sivrikaya, 2014).

$-0.212+0.038 \mathrm{~mm}$ boyut grubunda yapılan spiral ile zenginleştirme deneyleri sonucunda elde edilen temiz kömürün karbon içeriği değerleri Şekil 4'de ve yanabilir verim değerleri Şekil 5'de verilmiştir.

Şekil 4 incelendiğinde, katı oranının artışına bağlı olarak karbon içeriği azalmakla birlikte besleme debisinin artış1 önemli bir değişikliğe neden olmamıştır. Şekil 5 incelendiğinde ise 10 1/dk ve 15 l/dk besleme debilerinde katı oranının artışı, yanabilir verimde önemli bir değişikliğe neden olmamıştır. 5 1/dk besleme debisinde çalışıldığında, \%20 katı oranına kadar yanabilir verimde artış daha belirgin iken, bu katı oranının üstünde hafif bir azalma görülmektedir. Debi artışına bağlı olarak ise yanabilir verimde artış olmaktadır. Dolayısıyla, $0.212+0.038 \mathrm{~mm}$ boyut grubunda optimum deney koşulları, \%20 katı oranı ve 15 1/dk besleme debisi olarak kabul edilmiştir. Bu şartlarda \%50.98 karbon içerikli temiz kömür \%89.12 yanabilir verim ile kazanılmıştır.

Çok ince boyut grubunda spiral ile yapılan zenginleştirme çalışmaları oldukça sınırlı kalmıştır. Honaker vd. (2007), -210+0.044 mm boyutlu, \%33.5 küllü kömürü kullanarak \%12 katı oranı ve 60 1/dk besleme akış hızı şartlarında yaptı̆̆ 1 spiral deneyleri sonuçlara göre, \%11.71 küllü temiz kömürü \%84 yanabilir verim ile kazanmıştır. Deneylerde katı oranının azalması ve besleme akış hızının artışıyla optimum sonuçların elde edildiği belirtilmiştir.

$-1+0.212 \mathrm{~mm}$ ve $-0.212+0.038 \mathrm{~mm}$ boyut grubundaki beslemenin kül içeriği değeri sırasıly \%22.01 ve \%53.85'dir. Dolayısıyla elde edilen karbon içeriği değerlerinin düşük olması, besleme kül miktarından da kaynaklanmaktadır. Bununla birlikte boyutun azalmasıyla, şiste gitmesi gereken ağır-ince taneler hatve dış çeperine doğru gitmiş ve böylece ince boyut grubunda katı oranı artışına bağlı olarak karbon içeriği değerleri azalmış yanabilir verim ise artmıştır.

Spiral ile zenginleştirme sonucunda elde edilen ürünler ile $+1 \mathrm{~mm}$ ve $-0.038 \mathrm{~mm}$ boyutlarındaki artıkların karbon içeriği, yanabilir verim ve ÜID değerleri, karşılaştırma yapabilmek amaciyla toplu olarak Tablo 3 'te verilmiştir.

Tablo $\underline{3}$ 'e göre, deneylerden elde edilen her iki konsantre ile $+1 \mathrm{~mm}$ 'lik ürünün birleştirilmesi sonucunda $\% 68.98$ oranında karbon içeriği içerikli lave $\% 56.77$ yanabilir verim ve $4712.31 \mathrm{kcal} / \mathrm{kg}$ üst 1 sıl değeri ile elde 
edileceği görülmüştür. Buna göre, Tablo $\underline{1}$ 'e bakıldığında elde edilen lave kömürün termik santralde kullanılabileceği belirlenmiştir.

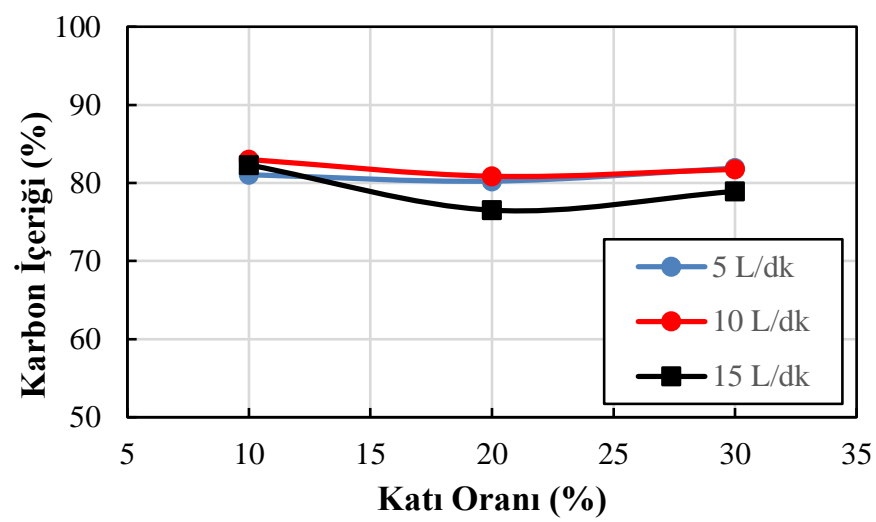

Şekil 2. $-1+0.212 \mathrm{~mm}$ boyutuna ait katı oranı değişiminin karbon içeriği miktarına etkisi

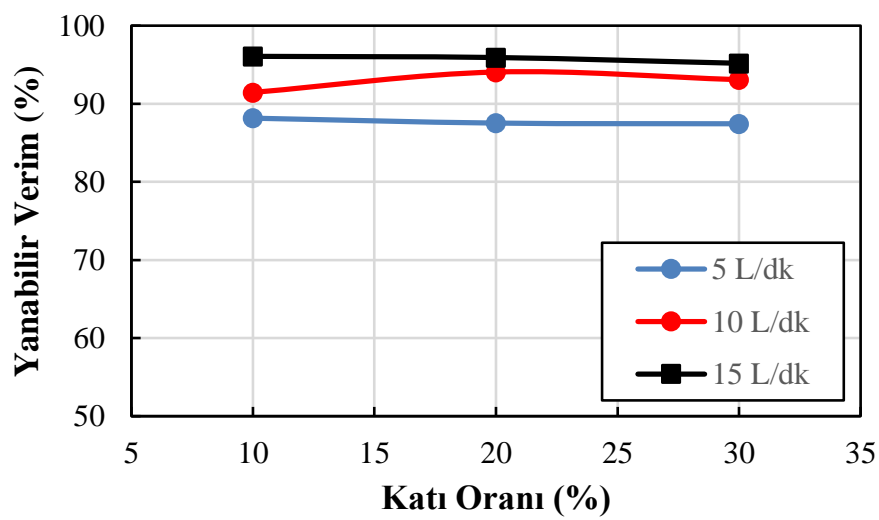

Şekil 3. $-1+0.212 \mathrm{~mm}$ boyutuna ait katı oranı değişiminin yanabilir verime etkisi

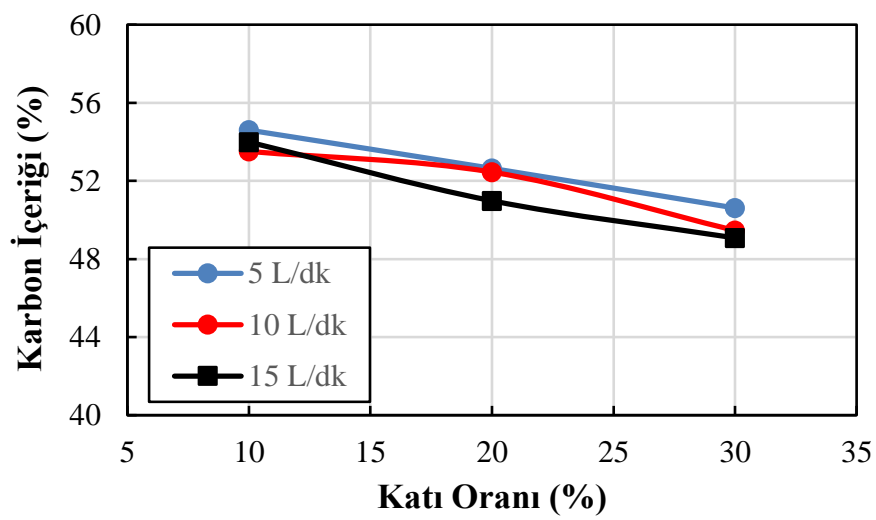

Şekil 4. $-0.212+0.038 \mathrm{~mm}$ boyutuna ait katı oranı değişiminin karbon içeriği miktarına etkisi

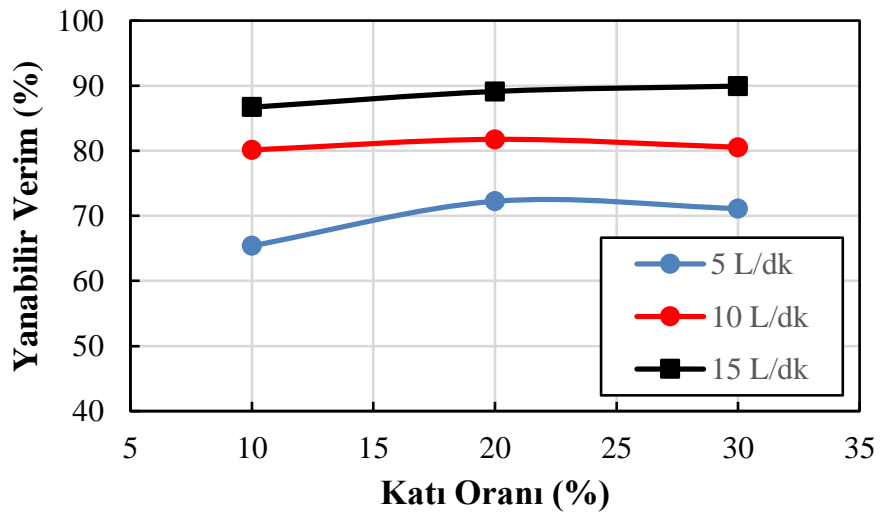


Şekil 5. $-0.212+0.038 \mathrm{~mm}$ boyutuna ait katı oranı değişiminin yanabilir verime etkisi

Tablo 3

Artık barajı numunesinden elde edilen ürünlerin birleștirilmiş sonuçları

\begin{tabular}{l|lcccc}
\hline $\begin{array}{c}\text { Tane Boyutu } \\
(\mathrm{mm})\end{array}$ & Ürün & $\begin{array}{c}\text { Ağırlık } \\
(\%)\end{array}$ & $\begin{array}{c}\text { Karbon İçeriği } \\
(\%)\end{array}$ & $\begin{array}{c}\text { Yanabilir Verim } \\
(\%)\end{array}$ & $\begin{array}{c}\text { ÜID } \\
(\mathrm{Kcal} / \mathrm{kg})\end{array}$ \\
\hline+1 & & 4.62 & 77.84 & 11.16 & 5521 \\
$-1+0.212$ & Konsantre & 11.48 & 81.74 & 29.13 & 5624 \\
& Artık & 1.45 & 48.22 & 2.17 & \\
$-0.212+0.038$ & Konsantre & 10.41 & 50.98 & 16.48 & 3348 \\
-0.038 & Artık & 2.49 & 25.98 & 2.01 & \\
Besleme & & 69.55 & 18.09 & 39.05 & 1603 \\
\hline
\end{tabular}

Aynı numunenin geniş tane boyutu aralığında $(-1+0.038 \mathrm{~mm})$ spiral kullanılarak yapılan ön çalışmada \%73.69 karbon içerikli lave \%81.75 yanabilir verim ile kazanılmıştır. Elde edilen lavenin $+1 \mathrm{~mm}$ boyutlu zenginleştirilmemiş ürün ile birleştirilmesi sonucu \%74.51 karbon içerikli lave $\% 52.70$ yanabilir verim ile elde edilmiştir (Karaca vd., 2018). Bu çalışmadaki birleştirilmiş sonuçlar ile ön çalışma sonuçları birbirine yakın olduğundan tek bir boyutta spiral zenginleştirmesi yapılması düşünülebilir. Fakat $-1+0.212 \mathrm{~mm}$ boyut grubunda daha kaliteli ürün elde edildiği için boyut gruplarının ayrı ayrı spirallerde zenginleştirilmesi uygun olacaktır.

Çalışmalar sonucunda elde edilen optimum değerlere bağlı olarak oluşturulan işlem akım şeması Şekil $\underline{6}$ 'da verilmiştir.

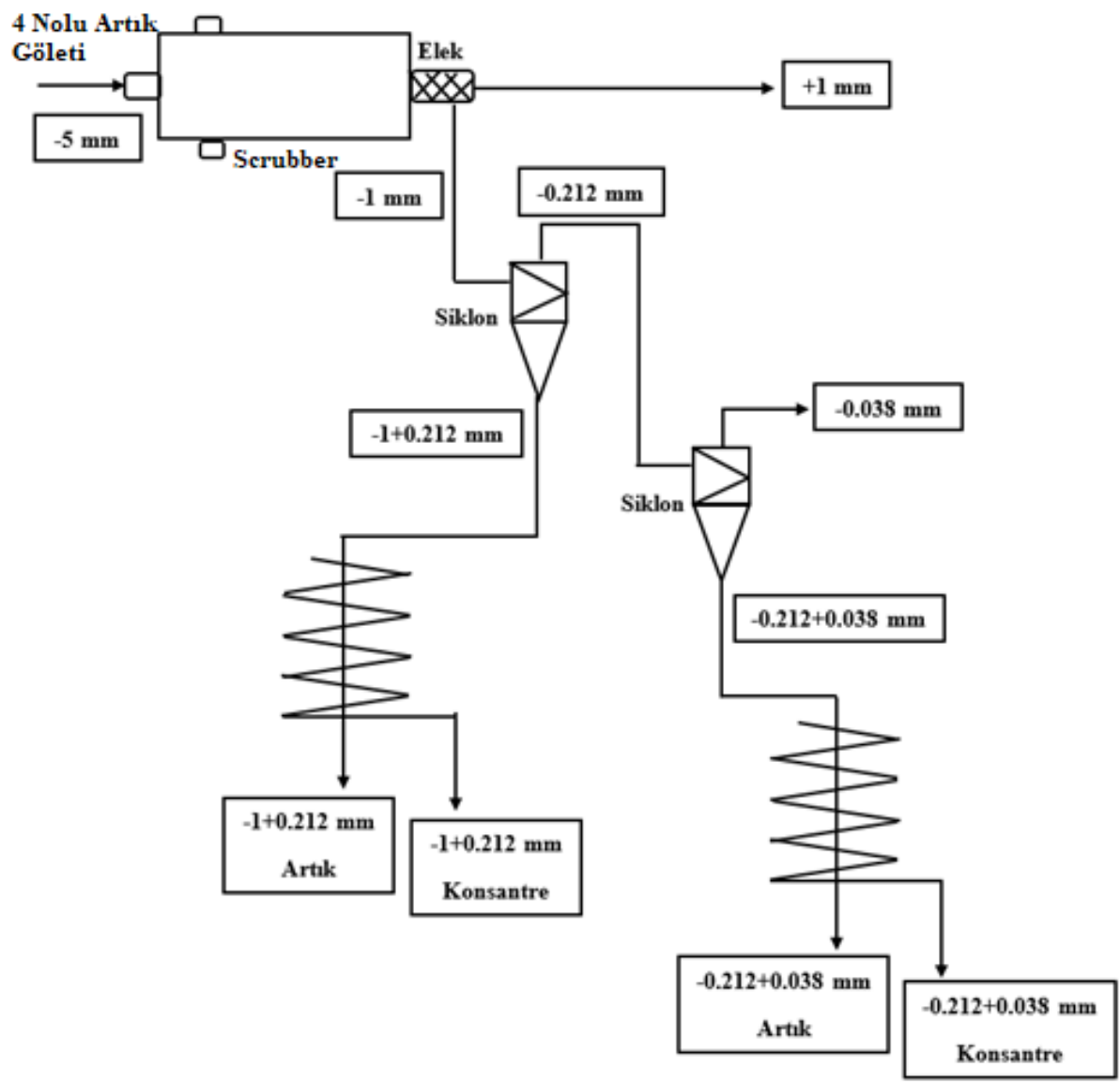

Şekil 6. Deneysel akım şemas1 


\section{Sonuçlar}

Bu çalışmada, GLİ'ye ait 4 Nolu şlam göletinden alınan numunedeki kömürün Humprey spirali kullanılarak kazanılabilirliğine tane boyutunun etkisi araştırılmıştır. Spiral ile yapılan zenginleştirme deneylerinde; $1+0.212$ ve $-0.212+0.038 \mathrm{~mm}$ boyut gruplarında 5,10 ve 15 1/dk'lık besleme debileri ile $\% 10, \% 20$ ve \%30'luk katı oranları kullanılmıştır.

$-1+0.212$ mm boyut grubunda optimum çalışma şartları \%30 katı oranı ve $10 \mathrm{l} / \mathrm{dk}$ besleme debisinde elde edilmiştir. Böylece \%81.74 oranında karbon içerikli temiz kömür $\% 93.09$ yanabilir verim ve $5521 \mathrm{kcal} / \mathrm{kg}$ üst 1sıl değeri ile kazanılmıştır. $-0.212+0.038 \mathrm{~mm}$ boyut grubunda ise en iyi deney sonuçları $\% 20$ katı oranı ve 15 1/dk besleme debisinde çalışıldığı zaman elde edilmiştir. \%50.98 oranında karbon içeriği ile elde edilen temiz kömürün yanabilir verim değeri \%89.12 ve ÜID $3348 \mathrm{kcal} / \mathrm{kg}$ olarak belirlenmiştir. $-1+0.212 \mathrm{~mm}$ boyut grubunda zenginleştirmenin daha kolay iken, $-0.212+0.038 \mathrm{~mm}$ boyut grubunda daha zor olduğu görülmüştür.

Ara ürünün alınmadığı deneylerde, her iki boyuttan elde edilen konsantreler ile nispeten düşük küllü olan zenginleştirme işlemine girmemiş $+1 \mathrm{~mm}$ boyutlu malzeme birleştirildiği zaman, $\% 56.77$ yanabilir verimli \%68.98 oranında karbon içerikli temiz kömürün $4712.31 \mathrm{kcal} / \mathrm{kg}$ üst 1sıl değeri ile elde edileceği görülmüştür. Birleştirilmiş bu ürünün termik santrallerde kullanılabileceği tespit edilmiştir.

Çalışma sonucunda elde edilen birleştirilmiş ürün değerlerinin ön çalışma sonuçları ile benzerlik gösterdiği saptanmıştır. Bununla birlikte ayrı ayrı zenginleştirme yapıldığında üst boyutlarda daha kaliteli lave elde edildiği belirlenmiştir.

\section{Teşekkür}

Çalışmamızda yardımlarını bizden esirgemeyen Türkiye Kömür İşletmeleri Garp Linyitleri İşletmesi Müessese Müdürlüğü yetkililerine teşekkür ederiz.

\section{Yazar Katkıları}

Ali Uçar: Kavramsallaştırma, yazım-orijinal taslak, araştırma, görselleştirme, deneylerin yapılması, kontrol işlemlerini gerçekleştirmiştir.

Sevgi Karaca: Kavramsallaştırma, yazım-orijinal taslak, araştırma, görselleştirme, deneylerin yapılması işlemlerini gerçekleştirmiştir.

Nezahat Ediz: Kavramsallaştırma, yazım-orijinal taslak, araştırma, deneylerin yapılması işlemlerini gerçekleştirmiştir.

Oktay Şahbaz: Kavramsallaştırma, yazım-orijinal taslak, araştırma, deneylerin yapılması işlemlerini gerçekleştirmiştir.

İ.Göktay Ediz: Kavramsallaştırma, yazım-orijinal taslak, araştırma işlemlerini gerçekleştirmiştir.

\section{Çıkar Çatışması}

Yazarlar çıkar çatışması bildirmemişlerdir.

\section{Kaynaklar}

Burt, R.O. (1984). Gravity Concentration Technology. New York: Elsevier Science Publishing Company Inc. Erişim adresi: https://books.google.com.tr/books/about/Gravity_Concentration_Technology. html?id= Mo2PnQAACAAJ\&redir_esc=y

Chaurasia, RC., Nikkam, S. (2016). A suitable process for clean coal recovery from tailing pond deposits. Energy Sources, Part A Recover Util Environ Eff., 38, 3435-3439. Erişim adresi: https://www.tandfonline.com/doi/full/10.1080/15567036.2016.1156197

Çiçek, T., Cöcen, I., Engin, VT., Cengizler, H. (2008). An efficient process for recovery of fine coal from 
tailings of coal washing plants. Energy Sources, Part A Recover Util Environ Eff., 30, 1716-1728. Erişim adresi: https://www.tandfonline.com/doi/abs/10.1080/15567030701443533

Erdem, A., Gülmez, A., Altun, O., Toprak, S., Olgun, Z., Gitmez, A. (2012). Fine Coal Recovery from The Ömerler Washery Tailings and Plant Applications, XIII. International Mineral Processing Symposium (pp. 759-764). Bodrum, Turkey. Erişim adresi: https://www.yumpu.com/en/document/view/5809093/ fine-coal-recovery-from-the-omerler-washery-tailings-and-plant-

Falconer, A. (2003). Gravity Separation: Old Technique/New Methods. Physical Separation in Science and Engineering, 12(1), 31-48. Erişim adresi: http://downloads.hindawi.com/archive/2003/812865.pdf

Glass, H.J., Minekus, N.J., Dalmun, W.L. (1999). Mechanics of coal spirals. Minerals Engineering, 12(3), 271-280. Erişim adresi: https://www.sciencedirect.com/science/article/abs/pii/S0892687599000059

Güney, A., Ateşok, G., Önal, G., Altaş, A. (1996). Kömür Zenginleştirme Teknolojisindeki Yenilikler. İstanbul: III. Kömür Teknolojisi ve Kullanımı Semineri, Yurt Madenciliği Geliştirme Vakfı Yayınları, Önal ve Ateşok (Ed.). Erişim adresi: http://www.maden.org.tr/resimler/ekler/3008b2c6f5370b7_ek.pdf

Holland-Batt, A.B. (1995). Some Design Considerations for Spiral Separators. Minerals Engineering, 8(11), 1381-1395. Erişim adresi: https://www.sciencedirect.com/science/article/abs/pii/089268759500104X

Honaker, RQ., Wang, D., Ho, K. (1996). Application of the Falcon Concentrator for fine coal cleaning. Minerals Engineering, 9, 1143-1156. Erişim adresi: https://www.sciencedirect.com/science/ article/abs/pii/0892687596001082?via\%3Dihub

Honaker, R.Q., Jain, M., Parekh, B.K., Saracoglu, M. (2007). Ultrafine coal cleaning using spiral concentrators. Minerals Engineering, 20, 1315-1319. Erişim adresi: https://www.sciencedirect.com/science/ article/abs/pii/S089268750700221X

IEA (2018).Coal information (Rapor). Erişim adresi: https://www.oecd-ilibrary.org/energy/coal-information2018_coal-2018-en

Karaca, S., Şahbaz, O., Ediz, İ.G., Uçar, A., Ediz, N., Şensögüt, C. (2018). Garp Linyitleri İşletmesi Artıklarından Humprey Spirali ile Kömürün Kazanılabilirliğinin Araştırılması. Türkiye 21. Uluslararası Kömür Kongresi (s. 327-336), Zonguldak, Türkiye. Erişim adresi: https://www.maden.org.tr/ resimler/ekler/1a9409a2200f285_ek.pdf

Koca, H., Koca, S., Karaoglu, M. (2000). Recovering of fine coal particles from tailing ponds of TKİ AlpagutDodurga coal washing plant. In: Hicyilmaz C. (Ed.), Miner. Process. Verge 21st Century (pp. 427-431), Antalya, Turkey. Erişim adresi: https://www.taylorfrancis.com/chapters/recovering-fine-coal-particlestailing-ponds-tki\%CC\%87-alpagut-dodurga-coal-washing-plant-koca-koca-karao\%C4\%9Flu/e/10. 1201/9780203747117-73

Meenan, G.F. (1999). Modern coal flotation practices. In: Advances in Flotation Technology, B.K. Parekh, and J.D. Miller, (Ed.). Denver: SME. Erişim adresi: https://www.osti.gov/biblio/20050677

Öney, Ö., Tanrıverdi, M., Çiçek, T. (2014). Zonguldak ince kömürlerinin spiral ayırıcı ile zenginleştirilmesi. Türkiye 19. Kömür Kongresi (s. 217-225), Zonguldak, Türkiye. Erişim adresi: http://www.maden.org.tr/ resimler/ekler/2ab23ac2430cc38_ek.pdf

Özgen, S., Malkoç, Ö., Doğancik, C., Sabah, E., Şapçi, FO. (2011). Optimization of a Multi Gravity Separator to produce clean coal from Turkish lignite fine coal tailings. Fuel, 90, 1549-1555. Erişim adresi: https://www.sciencedirect.com/science/article/abs/pii/S0016236110006393?via\%3Dihub

Peer, F., Mongwe, A., Van Heerden, J.H.P. (2002). A preliminary investigation into the metallurgical efficiency of an enhanced gravity separator. The South African Institute of Mining and Metallurgy, 4, 251-254. Erişim adresi: https://www.saimm.co.za/Journal/v102n04p251.pdf

Ramsaywok, P., Vermaak, M.K.G., Viljoen, R. (2010). Case Study: High capasity spiral concentrators. The Journal of the Southern African Institute of Mining and Metallurgy, 110(11), 637-642. Erişim adresi: https://www.researchgate.net/publication/290261494_Case_study_High_capacity_spiral_concentrators

Richards, R.G., Palmer, M.K. (1997). High capasity gravity seperators a review of current status. Minerals Engineering, 10(9), 973-982. Erişim adresi: https://www.sciencedirect.com/science/article/ abs/pii/S089268759700071X 
Sivrikaya, O. (2014). Cleaning study of a low-rank lignite with DMS, Reichert spiral and flotation. Fuel, 119, 252-258. Erişim adresi: https://www.sciencedirect.com/science/article/abs/pii/S0016236113011320

TKİ (2019). Türkiye Kömür İşletmeleri Kurumu-2019 Kömür (Linyit) sektör raporu (Rapor). Erişim adresi:http://www.tki.gov.tr/depo/2019\%20K\%C3\%96M\%C3\%9CR\%20SEKT\%C3\%96R\%20RAPO RU\%20(1).pdf

Uslu, T., Sahinoglu, E., Yavuz, M. (2012). Desulphurization and deashing of oxidized fine coal by Knelson concentrator. Fuel Processing Technology, 101, 94-100. Erişim adresi: https://www.sciencedirect.com/ science/article/pii/S0378382012001233 